\title{
Morphological Control: Properties and Applications of Metal Nanostructures
}

\author{
Supat Chupradit $\mathbb{D}^{1},{ }^{1}$ M. Kavitha, ${ }^{2}$ Wanich Suksatan $\mathbb{D}^{3},{ }^{3}$ Mohammad Javed Ansari $\mathbb{D}{ }^{4}$ \\ Zuhair I. Al Mashhadani, ${ }^{5}$ Mustafa M. Kadhim, ${ }^{6,7,8}$ Yasser Fakri Mustafa (D), \\ Shafik S. Shafik, ${ }^{10}$ and Ehsan Kianfar ${ }^{11,12}$ \\ ${ }^{1}$ Department of Occupational Therapy, Faculty of Associated Medical Sciences, Chiang Mai University, \\ Chiang Mai,50200, Thailand \\ ${ }^{2}$ Saveetha Institute of Medical and Technical Sciences, Saveetha University, Chennai, India \\ ${ }^{3}$ HRH Princess Chulabhorn College of Medical Science, Chulabhorn Royal Academy, Bangkok, Thailand \\ ${ }^{4}$ Department of Pharmaceutics, College of Pharmacy, Prince Sattam Bin Abdulaziz University, Al-kharj, Saudi Arabia \\ ${ }^{5}$ Al-Nisour University College, Baghdad, Iraq \\ ${ }^{6}$ Department of Dentistry, Kut University College, Kut, Wasit 52001, Iraq \\ ${ }^{7}$ College of Technical Engineering, The Islamic University, Baghdad, Iraq \\ ${ }^{8}$ Department of Pharmacy, Osol Aldeen University College, Baghdad, Iraq \\ ${ }^{9}$ Department of Pharmaceutical Chemistry, College of Pharmacy, University of Mosul, Mosul, Iraq \\ ${ }^{10}$ Experimental Nuclear Radiation Group, Scientific Research Center, Al-Ayen University, Thi-Qar,64001, Iraq \\ ${ }^{11}$ Department of Chemical Engineering, Arak Branch, Islamic Azad University, Arak, Iran \\ ${ }^{12}$ Young Researchers and Elite Club, Gachsaran Branch, Islamic Azad University, Gachsaran, Iran
}

Correspondence should be addressed to Ehsan Kianfar; ehsan_kianfar2010@yahoo.com

Received 24 October 2021; Revised 19 November 2021; Accepted 18 January 2022; Published 22 February 2022

Academic Editor: Gianfranco Carotenuto

Copyright (c) 2022 Supat Chupradit et al. This is an open access article distributed under the Creative Commons Attribution License, which permits unrestricted use, distribution, and reproduction in any medium, provided the original work is properly cited.

\begin{abstract}
Metal nanomaterials with special physicochemical and plasmatic properties have a wide range of applications in various fields including catalysts, plasmon devices, spectroscopy, fuel cell, and various sensors including chemical, colorimetric, and fluorescence sensors. These applications are made possible by controlling the morphology and properties of nanostructures and increasing their selectivity. Various methods have been developed for the synthesis of metal nanostructures, including the use of prefabricated patterns or hard templates such as anodic aluminum oxide and soft molds such as cetyltrimethylammonium bromide (CTAB).
\end{abstract}

\section{Introduction}

In recent years, metal nanocrystals such as silver, gold, copper, due to their nanometer size, unique physicochemical properties, and surface plasmon behavior, have a high potential for use in various industries and technologies [1-3]. A small number of these nanocrystals have found special applications due to their special behavior in interacting with light. The study of the process of interaction between electromagnetic waves and conduction band electrons in metal nanoparticles is called plasmonic [4, 5]. Nanostructured plasmatic materials are known for their strong interaction with incoming light and free electrons. Here, metal nanostructures act as a source of conversion of light into a local electric field (electromagnetic excitation along with mass oscillations of free electrons) in metals, called localized superficial plasmonic [6,7]. These plasmatic interactions can be controlled by changing the morphology and dimensions of metal nanostructures [8-10]. Applications related to the field of nanoplasmatic include super 
lenses, Raman-enhanced surface spectroscopy (SERS), molecular spectroscopy, plasmonic-enhanced fluorescence, quantum computing, energy-dependent photochemical lithography, energy-assisted plasma ionization [11-15]. Silver is more than 50 times cheaper than gold, and because of its unique physicochemical properties, it is a good choice for use in plasmatic applications [16-18]. Gold nanoparticles, depending on their size, have good surface plasmon resonance (SPR) and show SPR absorption in the visible light region. Gold nano rods, gold nano cages, and hollow nanospheres have near-infrared absorption [19-21]. Surface-enhanced Raman scattering (SERS) is more suitable for silver nanostructures with sharp corners and edges than spherical (edgeless) silver nanoparticles [22-25]. Usually, 1-10 nm metal nanoparticles have good electron and optical effects due to their free electron path [26-28]. Therefore, by controlling the structural factors, their potential applications for use in the fields of catalytic processes, electronics, photonics, sensors, medicine, etc. can be improved [29-32]. The optical properties of metal nanostructures are highly dependent on their size and shape $[33,34]$. The controlled morphology of nanostructures is an important factor that has a strong impact on their unique plasmonic properties. Until now, various methods are adopted for the preparation of controlled size and shape of nanostructures [35]. In general, metal/silver salt precursor is mixed with reducing agent in the presence of stabilizing agent and control the size and shape of metal nanostructures. Past research publications show that silver nitrate, as a precursor, has been abundantly used due to its cheap price and easy availability [36-39]. Various reducing agents such as sodium citrate, sodium borohydride, and alcohols are widely used to reduce metal/Ag+ ions present in solution into metal/silver atoms which combine to make aggregates and finally become nanostructures. On the other hand, stabilizing agents are introduced to control and stabilize the required morphology of metal nanostructures [40-42]. However, in photochemical synthesis, a variety of light irradiation methods are adopted to synthesize metal nanostructures $[43,44]$. Following is the detail of chemical/photochemical synthetic processes [45]. Various methods are used to produce metal nanostructures, which are summarized in Figure 1.

1.1. Light-Mediated Synthesis. In this technique, light irradiation is applied to produce nanostructures. An example is laser ablation or direct laser irradiation on an aqueous solution of metal salt in the presence of surfactants to fabricate specific shape and size distribution of metal nanoparticles where the source of light works as a reducing agent. Laser light is also used to modify metal nanoparticles by simple melting such as silver nanospheres into silver nanoplates, and it is known as the tailoring process with light. Laser light-mediated synthesis is continuing its success for generating highly desirable and wellcontrolled metal nanostructures $[46,47]$.

1.2. Electrolysis and Pyrolysis. There are few scientific reports available describing use of the electrochemical approach for the synthesis of metal nanoparticles [48-50]. For example,

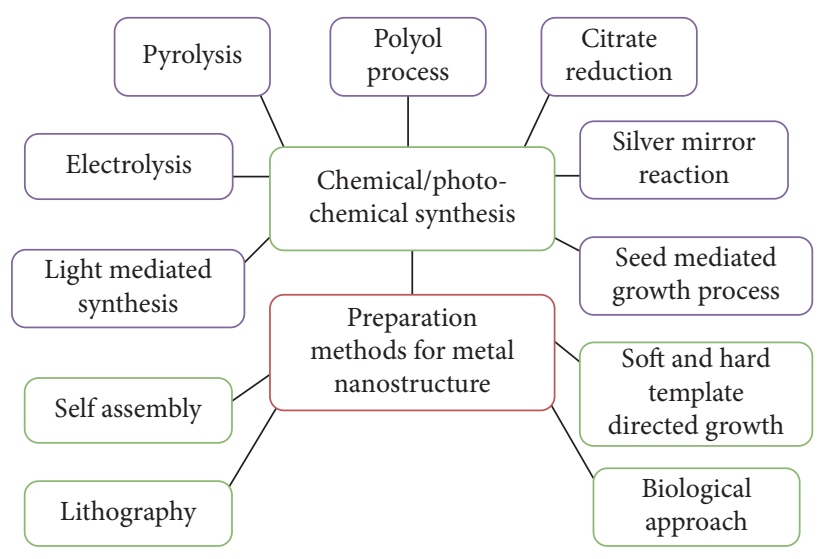

FIGURE 1: Different methods of synthesis of metal nanostructures [1].

spherical-shaped silver nanoparticles were synthesized with an average size of $10 \mathrm{~nm}$ by reducing silver ions in the presence of poly (vinyl pyrrolidone) (PVP) using the electrochemical method, where titanium (Ti) electrode worked as a cathode and platinum $(\mathrm{Pt})$ plate with $2 \mathrm{~cm}$ diameter worked as an anode [51-53]. Silver nanoparticles are also synthesized by adopting another method of spray pyrolysis in which an average grain size of $100 \mathrm{~nm}$ of silver nanopowder was synthesized [54-56]. Among other chemical syntheses, electrolysis and pyrolysis are considered environmental friendly processes as no harmful or toxic reducing agents are used to produce nanostructures [35].

1.3. Citrate Reduction. One of the popular methods to synthesize Ag colloidal solutions is citrate reduction of silver ions as we do not need comprehensive laboratory training skills [35]. First time, Lee and Meisel introduced this method in 1982 [181]. Generally, Ag nanoparticles are formed, when a calculated amount of sodium citrate is added in an aqueous solution of silver nitrate at boiling and kept for at least $1 \mathrm{~h}$ [57-59]. This is a very simple method but did not produce a confined size of nanoparticles. The synthesized product shows a variety of sizes in the range of 20-600 $\mathrm{nm}$ [60-62]. However, $\mathrm{pH}$ control is an important factor, as few shapecontrolled methods had been discussed by previous researchers by controlling $\mathrm{pH}$ values such as at $\mathrm{pH}=5.7$ triangular shape and $\mathrm{pH}=11.1$ spherical as well as rod-like particles were formed [35].

1.4. Polyol Synthesis. Synthesized Ag nanostructures can be classified into different classes based on their properties, shape q s, or sizes [184]. In general, silver salt precursor and capping agents are introduced into polyols for the generation of nucleation and growth towards silver nanostructure [63-66]. Propylene glycol, 1,2-propylene glycol, or 1,5pentanediol are commonly used reducing agents which reduce silver ions present in the solution [35]. Reaction parameters such as temperature and concentrations are very important to overcome the possible control on the final reaction product $[67-70]$. 
1.5. Seed-Mediated Synthesis. In recent years, another approach to synthesize metal nanoparticles gaining much attention is seed-mediated synthesis in which nanocrystals work as seeds for further growth [71-73]. This method has advantages on the control over the end product morphology. For example, Xia et al., in 2010, synthesized silver nanotubes by using the spherical- or cubic-shaped single-crystal seed for specific edge length from 30 to $200 \mathrm{~nm}$ [74-77].

1.6. Silver Mirror Reaction. Justus von Liebig discovered a silver mirror reaction in 1835 which became much popular for depositing Ag metal on targets or solid surfaces. In this reaction, Tollen's reagent $\left[\mathrm{Ag}\left(\mathrm{NH}_{3}\right)_{2} \mathrm{OH}\right]$ is reduced by sugar or any aldehyde-containing compound for generating silver:

$\mathrm{RCHO}+2\left[\mathrm{Ag}\left(\mathrm{NH}_{3}\right)_{2}\right]^{+}+2 \mathrm{OH}^{-}{ }^{-\mathrm{RCOOH}}+2 \mathrm{Ag}+4 \mathrm{NH}_{3}+\mathrm{H}_{2} \mathrm{O}$

The successful reaction shows shiny layer formation on the inner side of the reaction container due to the silver deposition. Silver mirror reaction is mostly employed for detecting the aldehyde group in schools.

\section{Synthesis of Metal Nanostructures with Controlled Morphology}

2.1. Hard Template. Hard mold is used to produce metal nanowires with unique magnetic properties. In this method, the porous mold acts as a scaffold, and various materials are placed inside its pores and form wired nanostructures [78-80]. The hard mold contains inorganic porous materials such as polymer membranes, anodic aluminum oxide, and carbon nanotubes $[9,10]$. The most commonly used hard molds are thin and porous anodic oxide films with various morphologies on aluminum sheets. Anodic aluminum oxide membranes are produced by the process of anodizing aluminum foil using acidic solutions [81, 82]. In anodic oxidation technology, the dimensions and distribution of the pores in the oxide thin film can be controlled [83]. Anodic aluminum oxide porous membranes with regular hexagonal pores have higher chemical and thermal stability and are therefore commonly used as a hard mold for the synthesis of metal nanowires [84, 85]. Also, the porosity density in these structures reaches $10^{11}$ holes per square centimeter $[12,13]$. The use of the electrochemical deposition method to fill the desired material inside porous membranes is a simple and flexible approach to the synthesis of one-dimensional nanostructures that have been used to produce various types of metal and semiconductor nanowires $[86,87]$. In general, the synthesis of nanomaterials inside hard mold spores has three main steps as follows [12-14]:

(A) Coating one side of the membrane using a thin metal layer by electrochemical deposition and using it as a plating electrode [88]

(B) Catholic deposition of ions of the desired material from inside the solution on the metal surface in the pore floor [89]

(C) Dissolution of anodic oxide molds in acid or base and obtaining separate metal nanowires [90]
A schematic of a common hard mold consisting of anodic aluminum oxide membranes is shown in Figure 2(a) [2]. Onedimensional channels with controllable length and diameter are filled with the desired materials, and then, regular nanowires are obtained by dissolving the mold in a solution of one molar $\mathrm{NaOH}[91,92]$. Figure 2(b) shows a scanning electron microscope image of anodic aluminum oxide molds with a pore diameter of $60 \mathrm{~nm}$ that can be dissolved in sulfuric acid solution [2]. The length and diameter of the pores as well as the distance between them in the mold can be controlled by changing the applied voltage and the electrolyte used in the anodizing process. Scanning electron microscope image of metal nanowires produced by hard molding method is shown in Figure 2(c) [2]. The synthesized nanowires are continuous and approximately parallel to a diameter of approximately $50 \mathrm{~nm}$, slightly smaller than the diameter of the mold spores $[93,94]$. This is because nanowires are compacted by removing water from their structure [95]. The higher the growth rate of nanowires, the more structural defects occur in nanowires [96]. Unlike soft mold synthesis, hard molded metal nanowires usually have a polycrystalline or polycrystalline structure. Since the magnetic nature of nanomaterials strongly depends on the degree of crystallinity of the structure, subsequent annealing heat treatment is usually used to improve the magnetic properties of nanowires produced by hard molding [97, 98]. Here, the porous alumina mold acts as a protective mold during the annealing operation of nanowires due to its high chemical and thermal stability $[99,100]$. A diagram of the synthesis of $\mathrm{CoPt}_{3}$ nanowires during the deposition process of cobalt and platinum atomic clusters is shown in Figure 3 on a thin film of amorphous or noncrystalline gold on the surface of the anodic oxide layer. In the early stages of $\mathrm{CoPt}_{3}$ growth, the buds are randomly oriented, and the atomic mass is deposited continuously in a completely random direction [101-103]. During the cobalt and platinum precipitation process, $\mathrm{CoPt}_{3}$ nanowires with lower crystallinity are formed with some porosity and internal stress [104]. Stress anisotropy directly leads to dimensional anisotropy and reduces magnetic coercively $[105,106]$. Therefore, the magnetic fields (indicated by arrows) will have a random and small orientation [15-18]. Heat treatment increases magnetic induction during structural failure or stress drop and reduces the number of defects [107-109]. Also, the magneto static vector is preferably positioned along the axis of the wire to reduce the magneto static energy $[110,111]$. Therefore, the direction of magnetization of nanometer arrays is in the direction of the axis of the nanowires and causes the magnetic inhibitory force $(\mathrm{HC})$ of the parallel field to be greater than the $\mathrm{HC}$ of the field perpendicular [112-114]. By heating or so-called annealing of $\mathrm{CoPt}_{3}$ nanowires at $400^{\circ} \mathrm{C}$, the nanowire structure will contain cobalt ferromagnetic nanoclusters in clusters $[115,116]$. Platinum atoms separate cobalt atomic clusters and facilitate the formation of cobalt nanoclusters with a single magnetic field $[117,118]$. By increasing the annealing temperature to $500^{\circ} \mathrm{C}$, $\mathrm{CoPt}_{3}$ nanowires maintain their cluster structure. Cobalt and platinum atoms begin to atomically migrate through the diffusion mechanism to form a regular structure (L12) $[119,120]$. This creates a strong ferromagnetic coupling between the Co and $\mathrm{Pt}$ atoms by hybridizing the $3 \mathrm{~d}$ cobalt and $5 \mathrm{~d}$ Pt orbitals, 

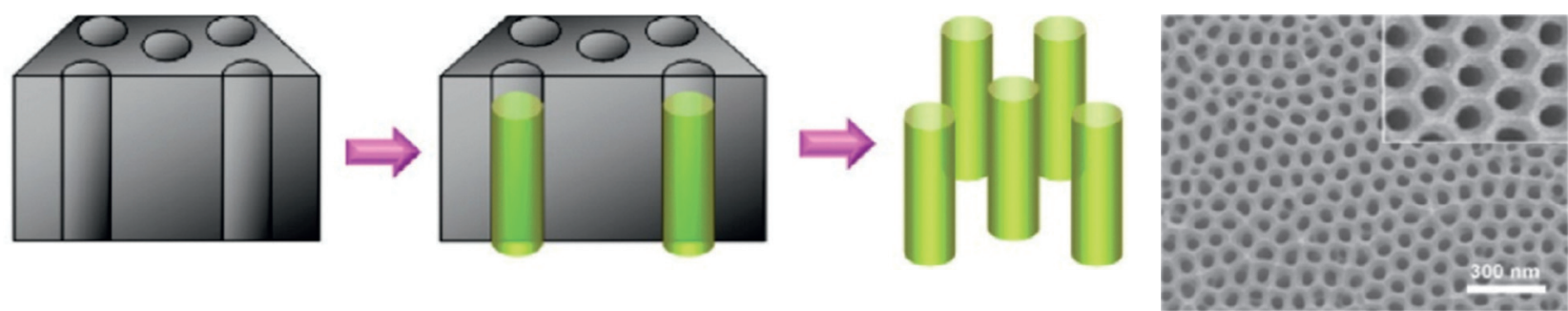

(a)

(b)

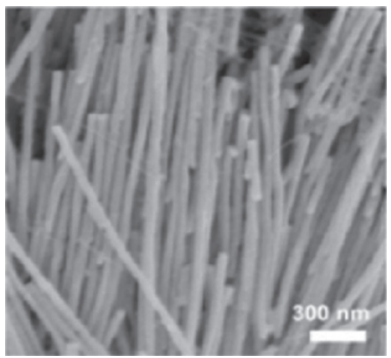

(c)

Figure 2: (a) Scheme of hard mold, (b) the scanning electron microscope image of anodic aluminum oxide mold, and (c) the scanning electron microscope image of $\mathrm{CoPt}_{3}$ nanowires produced by the hard mold method [2].
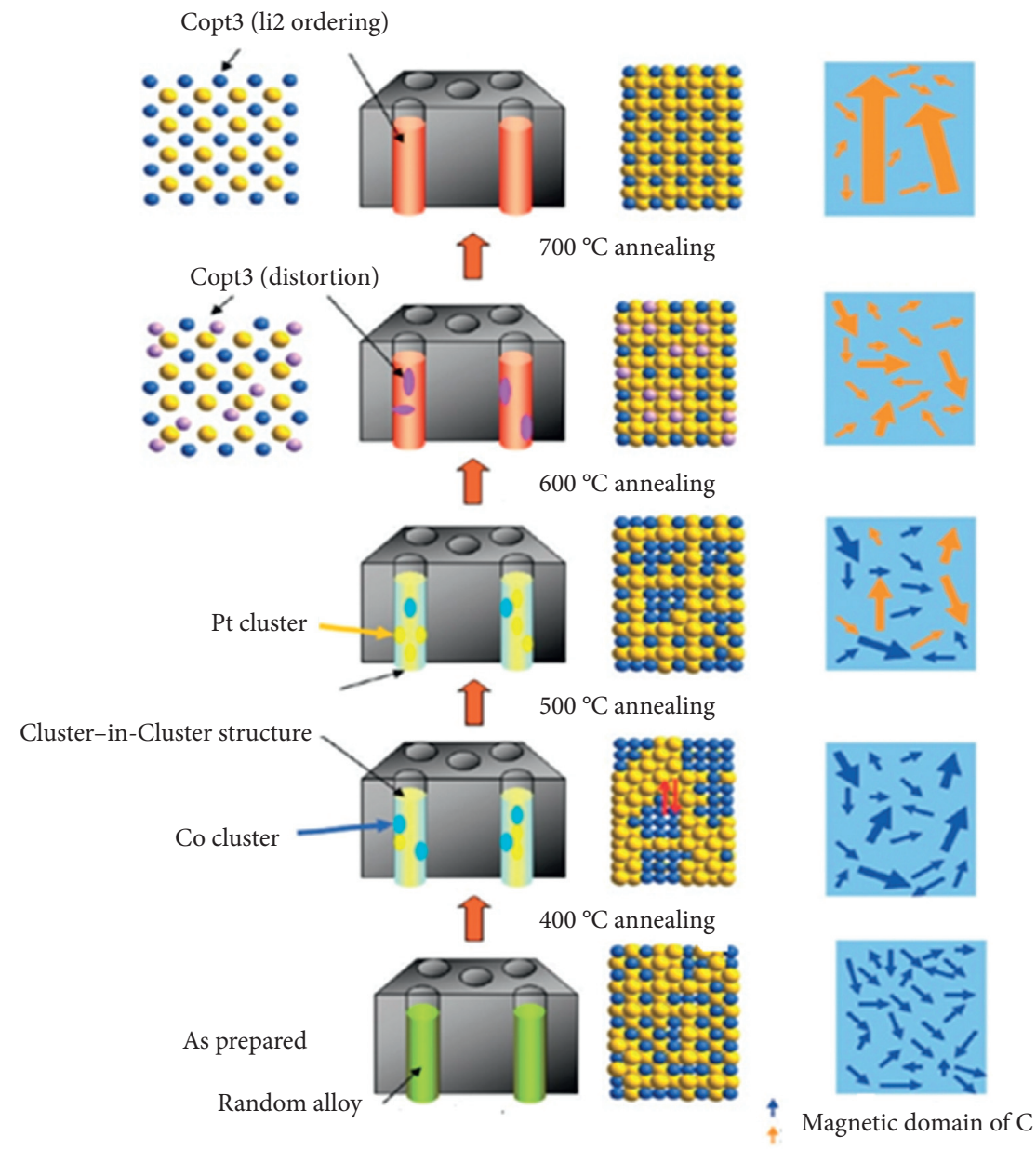

Figure 3: Schematic of the phase conversion steps of $\mathrm{CoPt}_{3}$ nanowires [26]. 
and the spin polarization of the Pt atoms [121]. Co clusters (blue arrows) and the regular structure of $\mathrm{CoPt}_{3}$ (yellow arrows) both play a role in improving the magnetic properties (increasing the $\mathrm{HC}$ triplet) of nanowires [122]. Finally, as the temperature rises to $700^{\circ} \mathrm{C}$, most $\mathrm{CoPt}_{3}$ nanowires form a regular, long-range structure. Reducing the density of defects and the number of grains in the growing $\mathrm{CoPt}_{3}$ leads to a significant increase in magnetic induction $[19,20]$. The hard die-casting process has been widely considered due to its high controllability in the precise production of one-dimensional nanomaterials, especially magnetic nanowires [123-125]. Also, significant progress has been made in the production of intermediate metal nanowires such as iron, cobalt, nickel, and their alloys using porous alumina molds $[126,127]$.

2.2. Soft Template. Soft molds refer to a set of surfactants or surfactants such as liquid crystals, micelles. Unlike hard molds, soft molds are of organic origin and contain ligands, surfactants, and polymers [128-131]. Using soft molds such as rod-shaped micelles, $\mathrm{Ag}$ and gold nanowires and nanowires with controllable diameters and dimensional ratios can be synthesized. Bar-shaped micelles are obtained by selfassembly of cetyltrimethylammonium bromide (CTAB) or liquid crystalline phases consisting of sodium bis (2-ethylhexyl) sulfosuccinate, para-xylene, and water [21-25]. Also, the two-layer acetyl amine/water system is used as a soft mold for the production of Ag nanosheets. Compared to the hard mold method, the rate of germination and growth reactions is slower in the soft mold method [132-134]. As a result, the rate of germination and growth is practically controllable, and distinct crystalline faces are clearly visible on the surface of the nanoparticles $[135,136]$. The morphology of metal nanostructures is highly sensitive to the temperature of the growth solution used in the soft molding method [26]. Ag diagram of the formation of gold nanostructures with different morphologies at different temperatures, along with transmission electron microscope images of each of them, is shown in Figure 4. At high temperatures, rapid reduction of $-\mathrm{AuCl}_{4}$ ions provides gold buds, and $C T A B$ interactions with these particles at high temperatures contribute to the growth of gold nanoparticles [137-139]. By changing the temperature, the growth kinetics of gold nanostructures can be controlled to produce nanosheets, icosahedral nanocrystals, spherical and hexagonal nanoparticles, and gold nanowires [28, 140, 141].

2.3. Sacrificial Template. In recent years, the synthesis and characterization of hollow nanomaterials due to its potential application have attracted much attention in the development of nanoscience and nanotechnology. Various methods have been developed for the synthesis of hollow inorganic nanomaterials, including the Ostwald processing process, the crackling effect, and the sacrificial mold [142-146]. The sacrificial mold method is an effective method for the preparation of hollow metal nanostructures [147]. The most important reaction in this method is the reaction between a reactive sacrificial mold and a reactant (neutral component). The reaction between these two compounds occurs at the mold surface [148]. The neutral component deposits on the surface of the mold and penetrates out of the pores. The morphology of the obtained hollow nanostructures is highly dependent on the shape of the sacrificial mold. Gold and silver are widely used in sacrificial molding reactions due to their special optical properties [149]. When a sacrificial mold of silver and gold tetrachloride $\left(\mathrm{AuCl}_{4}^{-}\right)$is mixed in an aqueous solution, because the standard potential of the $-\mathrm{Au} / \mathrm{AuCl}_{4}$ pair $(0.99$ Volts relative to the standard hydrogen electrode) is greater than the standard potential of the silver/silver pair ( 0.8 Volts relative to the standard hydrogen electrode), the silver atoms are oxidized to $\mathrm{Ag}+\mathrm{Ag}$ ions $[150,151]$. The galvanic substitution process is used to synthesize hollow gold nanospheres. In the first step, a layer of pure silver is deposited on the surface of the gold nanoparticles $[29,30]$. By depositing silver atoms directly on the surface of Au nanoparticles using an ascorbic acid reducing agent, gold-silver core-shell nanoparticles are obtained. The proximity of the atomic radii of silver and gold causes the germination and growth of silver atomic clusters on the surface of gold nanoparticles (Figure 5(a)). The second step is the galvanic substitution reaction between the shell and core colloids with aqueous $\mathrm{HAuCl} 4$ solution at room temperature. The chemical reaction is as follows [31-33]:

$$
3 \mathrm{Ag}+\mathrm{AuCl}-43 \mathrm{Ag}++4 \mathrm{Cl}-+\mathrm{Au}
$$

Figures 5(b) and 5(c) show gold nanoparticles, $\mathrm{Au}_{\text {core }}$ $\mathrm{Ag}_{\text {shell }}$ core-shell nanoparticles, and hollow gold nanoparticles, respectively. When silver nanoparticles are coated with a solution of gold ions, the pure layers of silver turn into gold nanoshells [29].

\section{Properties and Applications of Metal Nanoparticles}

3.1. Optical Properties and Applications. As mentioned, free electrons in metals are stimulated by light and oscillate collectively, which is called the superficial plasmon resonance process $[152,153]$. This mass oscillation can be effective in scattering and absorbing light in conditions of intensification and bright colors of metals, especially gold and silver $[154,155]$. When stimulated by light on a metal surface, the oscillation of the electrons causes the surface charges to polarize. Unlike the bulk mode, electric charges cannot be distributed on the surface of light-excited nanoparticles due to their short wavelength, which is called localized surface plasmon resonance (LSPR) [34, 36]. This phenomenon creates strong localized electric fields at the nanometer scale $[156,157]$. LSPR is used in the Raman scattering spectra of molecules and the detection of fingerprint spectra using chemical information. Due to their plasmatic behavior, gold and silver nanocrystals are used in Raman-enhanced surface dispersion spectroscopy (SERS) and molecular sensors [158-160]. Although each organic molecule has a specific Raman spectrum, signal amplification is important to detect low-concentration analyses $[161,162]$. To this end, the Raman signal of adsorbed molecules on the surface can be amplified by applying strong local electric fields by LSPR and metal nanocrystals [37]. 


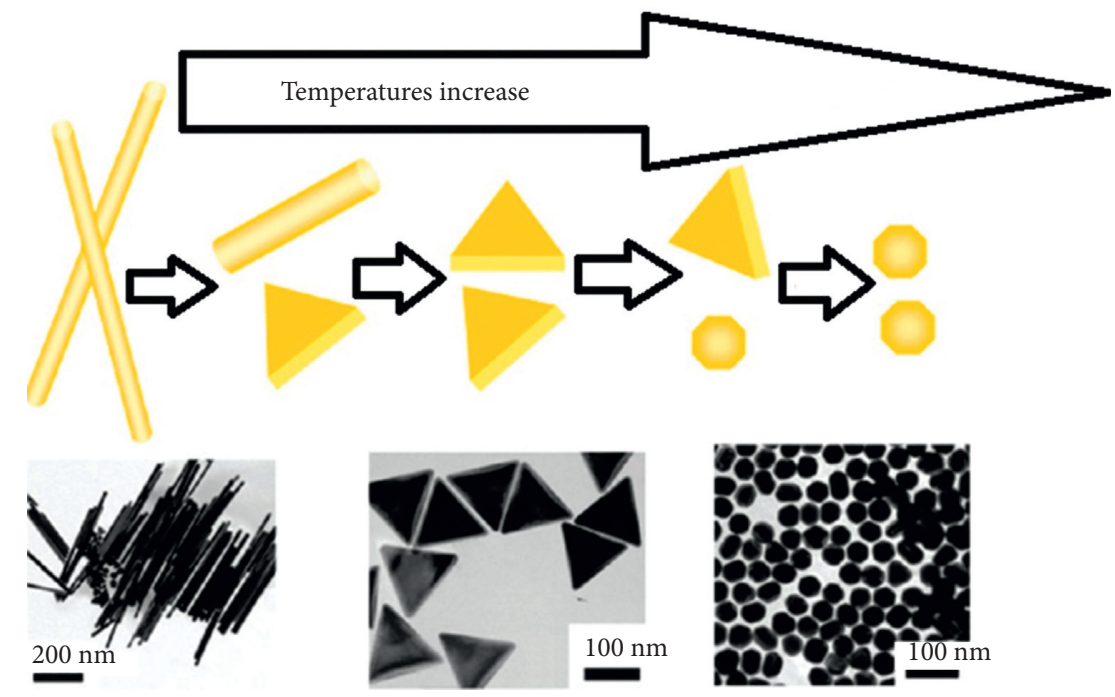

FIGURE 4: Scheme of gold nanostructures with different morphologies formed at different temperatures along with transmission electron microscope images related to them [28].

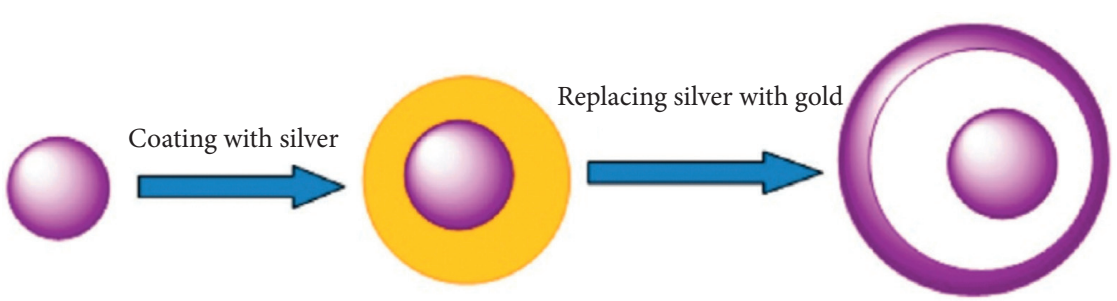

(a)

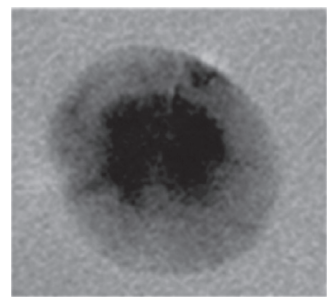

(c)

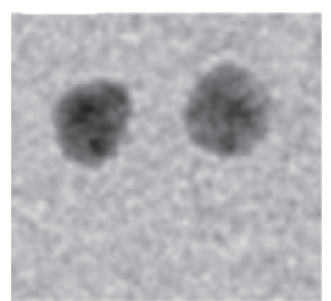

(b)

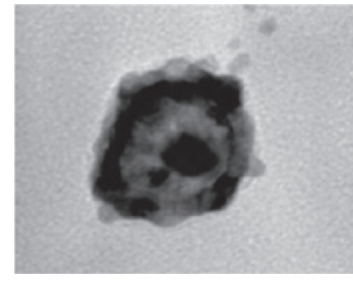

(d)

Figure 5: Schematic of the synthesis of hollow gold nanospheres during galvanic substitution with associated transmission electron microscope images [29].

3.2. Catalytic Properties and Applications. The use of metal nanoparticles is very beneficial to facilitate chemical reactions. These materials have good catalytic performance due to the high surface-to-volume ratio [163], [164, 165]. These metal nanocrystals with engineered structures are used as catalysts for oxidation reactions, carbon-carbon coupling, electron transfer, hydrogenation, etc. Even certain metal nanostructures have been used in industrial-scale catalytic applications [38]. It is worth noting that the reactivity and selectivity of this type of catalyst can be controlled by the morphology of nanocrystals [35]. In addition to the total surface area of the crystal, the morphology of the crystal also determines the number of atoms at the edges and corners of the crystal [35]. These factors affect their catalytic performance. Optimization of these factors should be considered as a criterion for evaluating the performance of nanocrystal line catalysts [35] which is also necessary to pay attention to the stability of nanoparticles and the factors covering the surface of nanocatalysts. In many cases, the atoms on the surface of nanocatalysts are very active and change their shape, dimensions, and lifespan during the catalytic reaction [35, 160-163]. Also, particle surface coating agents may inactivate catalytically active regions [35, 160-163].

3.3. Properties and Applications of Electronics. Some metal nanocrystals, such as silver nanowires and silver nanorods, have electronic applications due to their high thermal and electrical conductivity [35]. Measurement of resistance and electrical conductivity of silver nanorods with different lengths and diameters indicates that the conductivity of silver nanorods with a diameter of $20 \mathrm{~nm}$ is twice that of bulk conductors, and despite their very small size, these nanorods have extremely high electrical conductivity compared to 
bulk samples $[35,162,163]$. Therefore, metal nanocrystals with unique electronic properties are a very good choice for use in the manufacture of electrodes [39, 40].

3.4. Properties and Applications of Magnetism. Changing the dimensions and morphology of metal nanocrystals has a great impact on its fundamental magnetic properties [158]. As the size of nanocrystals decreases, new magnetic properties are observed. The property of superparamagnetic is one of the most important phenomena related to the size of magnetic nanoparticles [159-162]. The anisotropic magnetic energy barrier from the upward spin to the downward spin state for bulk materials is much larger than the thermal energy $\left(k_{\mathrm{T}}\right)$. The anisotropic magnetic energy barrier of a magnet is proportional to the product of a constant multiplication of magnetic anisotropy $\left(K_{\mathrm{u}}\right)$ in the volume of the magnet [163]. In the case of nanoparticles, however, the thermal energy of the nanoparticles is easily sufficient to reverse the direction of the magnetic spin, although it is not sufficient to overcome the spin-spin exchange coupling energy [35]. This behavior, in which the magnetic oscillation results in a total magnetization of zero, is called the superparamagnetic property, and the temperature at which the ferromagnetic to superparamagnetic conversion occurs is known as the blocking temperature $\left(T_{\mathrm{b}}\right)$ and is defined using the following relation [41, 42].

In this regard, $\mathrm{V}$ is the volume of the nanocrystal, $k$ is the temperature in Kelvin, and $T_{\mathrm{b}}$ is the critical temperature for converting ferrimagnets to super paramagnets, or the blocking temperature.

$$
T_{b}=\frac{K_{u} V}{25 K} .
$$

\section{Nobel Metal Nanomaterials}

4.1. Nanoelectrocatalysts Based on Noble Metal Nanostructures for Fuel Cell Applications. The development of nanomaterial synthesis methods has led to the production of various metal nanostructures with different dimensions, morphology, chemical composition, and antiparticle interactions [146]. These nanostructures provide a good opportunity to develop the application of active nanocrystals in fuel cell reactions. Platinum and platinum-based nanostructures are still the most effective electrocatalysts for fuel cell applications [147]. Small spherical nanoparticles are used as electrocatalysts in the oxidation reaction of small molecules because they have a high surface-to-volume ratio [149]. By reducing the dimensions of nanoparticles, their active surface increases, and therefore, in the structure of commercial electrocatalysts, platinum and palladium nanoparticles with very small dimensions $(3 \mathrm{~nm})$ are used [159]. It has also recently been shown that reducing the size of platinum nanoparticles plays a key role in increasing their catalytic activity. For example, platinum nanotubes synthesized using silver nanoparticles as a sacrificial mold have electrochemical activity and a longer lifespan than commercial catalysts [43].

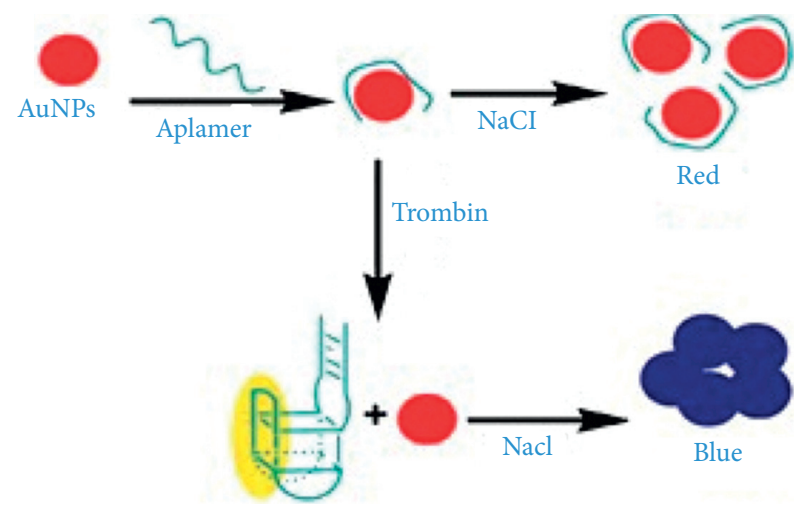

FIgURE 6: Gold nanoparticle colorimetric process for thrombin detection [30].

\subsection{Noble Metal Nanomaterials for Analytical Sensors}

4.2.1. Noble Metal Nanomaterials for Electrochemical Sensors. Advances in nanoscience have opened up new horizons in the field of electrochemistry [35]. The use of nanomaterials to make electrochemical sensors has increased their sensitivity and selectivity and has made it possible to detect target molecules based on various statistical analysis methods [160]. Improving the electrochemical sensitivity of these sensors requires the use of better electrode nanomaterials such as gold nanoparticles and mineral nanomaterials for electroanalytical applications. Because nanomaterials are able to increase the electrochemically active surface to absorb target molecules and facilitate electron transfer between the electrode and molecules and therefore create a higher response speed and higher sensitivity [42].

4.2.2. Noble Metal Nanomaterials for Calorimetry Sensors. Colorimetric sensors are attractive because of their simplicity, high sensitivity, and low price. These sensors can be coupled with UV-Vis spectroscopy to replace complex devices. The solution of gold nanoparticles is red but turns purple or blue after changing color in colorimetric sensors [116]. Therefore, at present, the color change of a solution of gold nanoparticles in colorimetric sensors is used to identify DNA, enzymatic activity, small molecules, metal ions, and proteins. Gold nanoparticles in combination with other molecules can provide a good sensor for detecting target molecules [119]. In optical sensors, silver nanoparticles are more useful because they have a higher absorption coefficient than gold nanoparticles with the same dimensions. Thus, the combination of silver nanoparticles with DNA molecules and other molecules results in the formation of a biodegradable colorimetric biosensor that is used to detect some important analyses. Unlike Au and Ag nanoparticles, $\mathrm{Pt}$ and Pd nanoparticles in the visible absorption spectrum do not have surface plasmon resonance (SPR) and therefore are not used in colorimetric sensors [120]. Figure 6 modifies a sensitive, simple colorimetric sensor based on aptameric (Aptameric, oligonucleotides synthesized from RNA or DNA or a combination of the two with other 


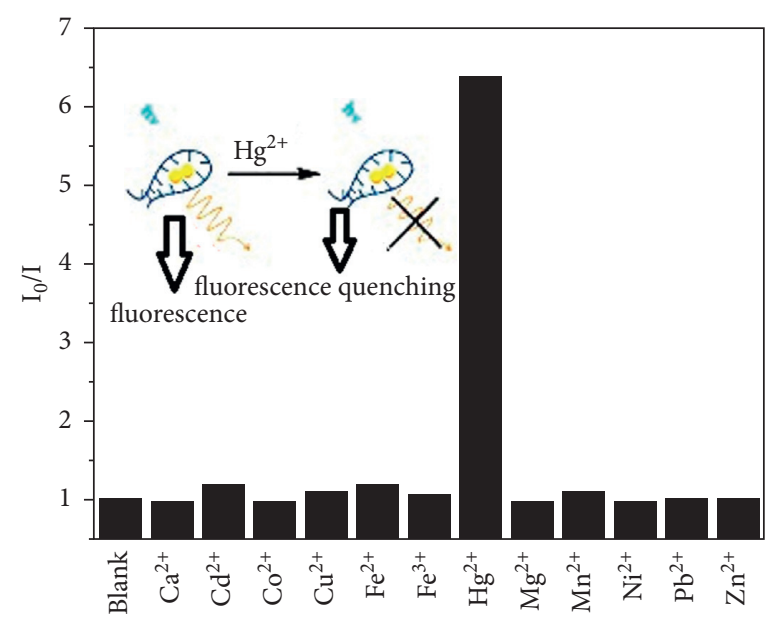

FIGURE 7: Fluorescence extinction mechanism for high-sensitivity $\mathrm{Hg}^{2}{ }^{+}$detection [31].
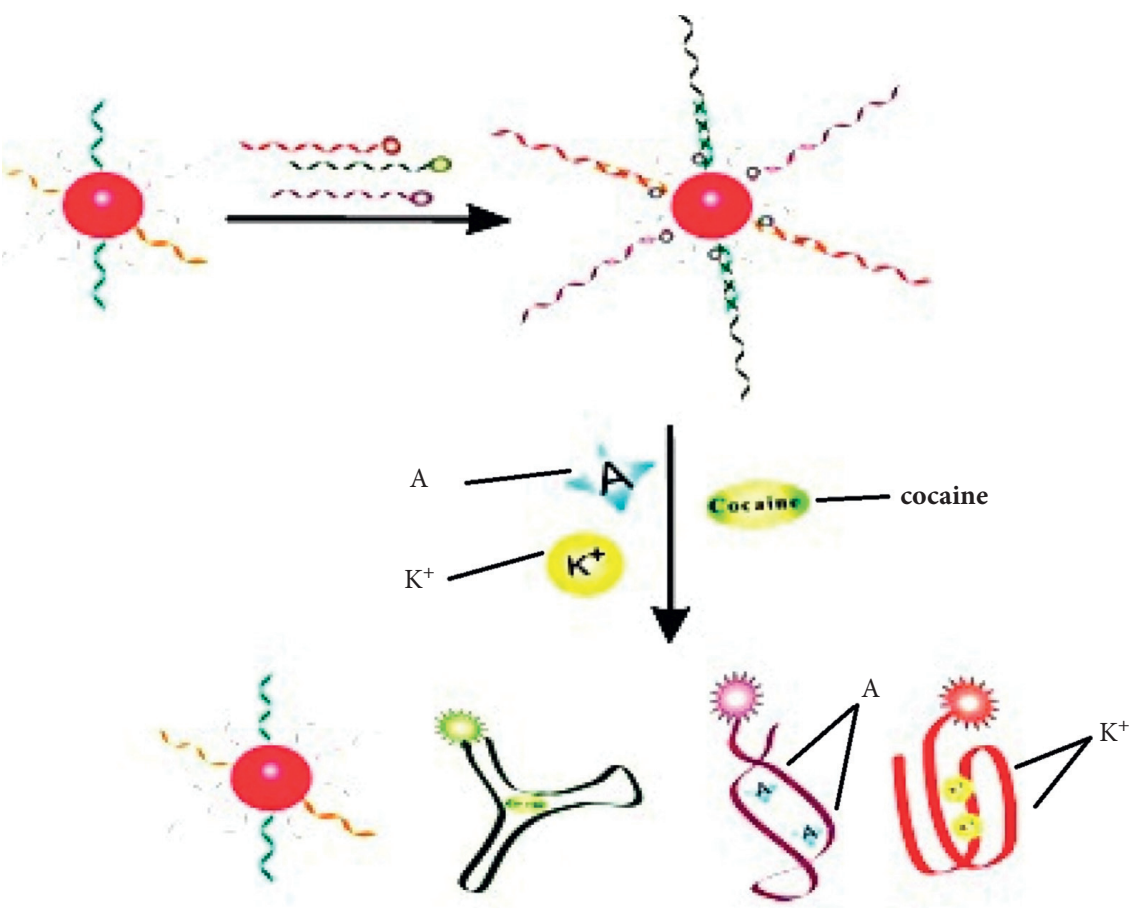

Figure 8: Multicolored gold nanoprobe for simultaneous detection of adenosine, potassium, and cocaine [42].

molecules) to detect thrombin (Thrombin, an enzyme needed for blood clotting) using gold nanoparticles. When thrombin is added to a solution of modified gold nanoparticles, thrombin interacts with aptameric on the surface of gold nanoparticles, and after adding a high concentration of sodium chloride salt, the color changes of the gold nanoparticles will be able to detect small amounts of thrombin [41-44].

4.2.3. Noble Metal Nanomaterials for Fluorescence Sensors. Fluorescence sensors are attractive because of their higher sensitivity and better performance than other optical methods. Recent advances in the field of synthesis and characterization of new metal nanomaterials have provided a good basis for the design of biochemical and fluorescence sensors [158]. In general, the design of fluorescence sensors based on metal nanomaterials is done in the following four ways $[35,162,163]$ :

(A) The use of fluorescence intensity reduction or "fluorescence quenching" processes of metal nanoparticles by target material molecules: various types of molecular interactions, including excited state reactions, molecular rearrangements, energy transfer, base state complex formation, and collisional or dynamic extinction, can lead to fluorescence extinction. For example, silver nanoparticles are used to detect mercury ions $\left(\mathrm{Hg}^{+2}\right)$ with low detection limits and high selectivity (Figure 7) [31]. 


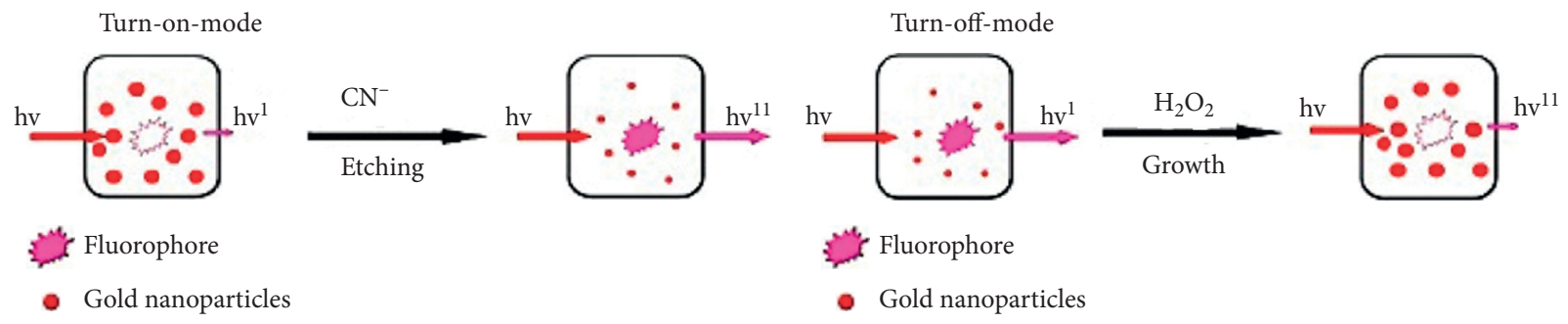

(a)

(b)

FIGURE 9: Scheme of IFE-based fluorescence detection process for hydrogen cyanide and hydrogen peroxide [43].

Elements of a Biosensor

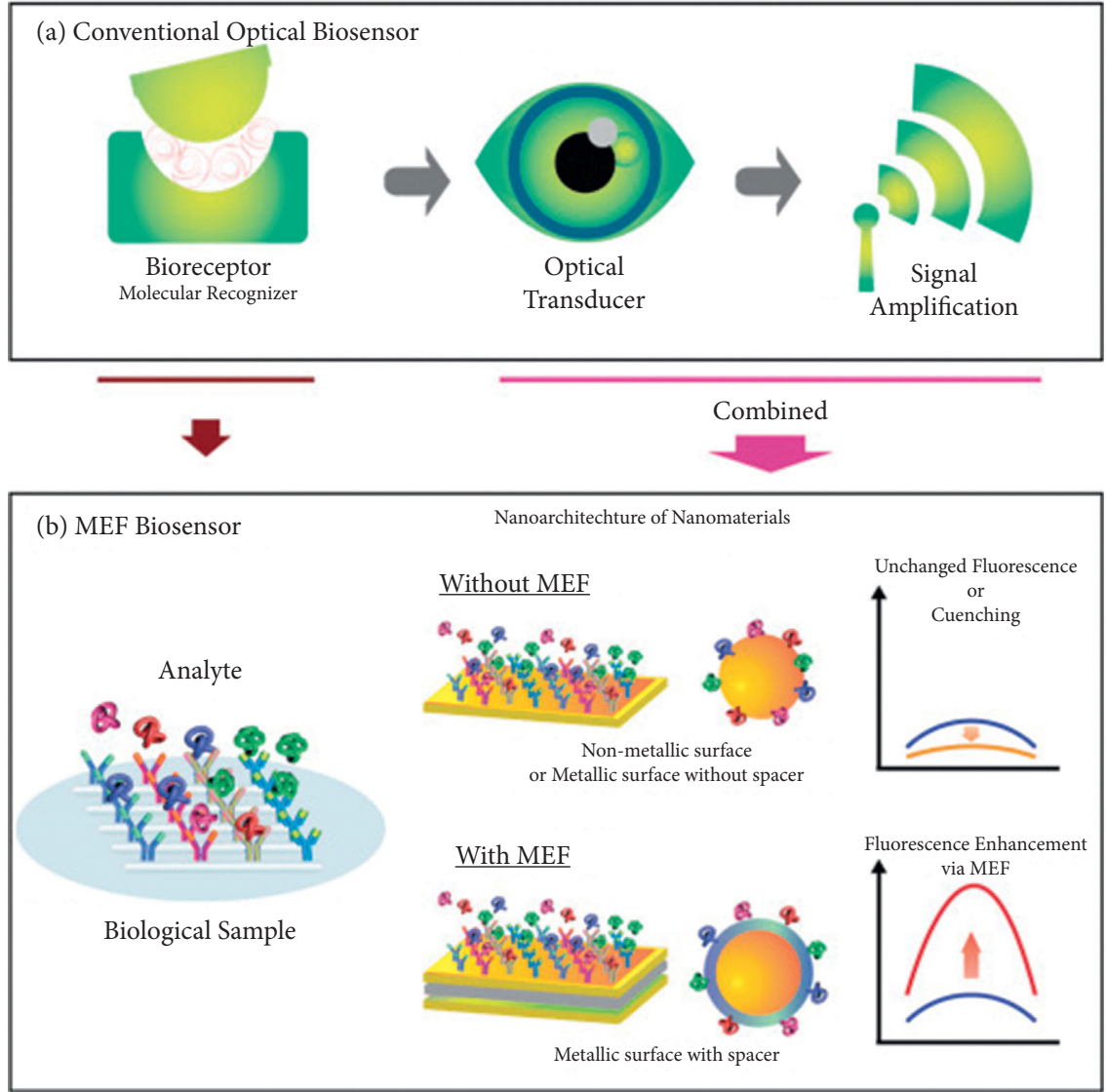

FIGURE 10: Scheme of metal-enhanced fluorescence (MEF) [44].

(B) Fluorescence quenching of metal nanoparticles by electron/nonradiative energy transfer mechanism: for example, gold nanoprobes are used to simultaneously identify three analyses of combined adenosine $(\mathrm{A})$, potassium ion $\left(\mathrm{K}^{+}\right)$, and cocaine, using multiple dyes (Figure 8) [31].

(C) Inner filter effect (IFE) fluorescence based on metal nanoparticles: here, metal nanoparticles act as fluorescence adsorbents for fluorophore emission units (fluorescence generators). It has been shown that gold nanoparticles can be used as a strong adsorbent in IFE fluorescence to detect cyanide $(-\mathrm{CN})$ and hydrogen peroxide $\left(\mathrm{H}_{2} \mathrm{O}_{2}\right)$ (Figure 9) [42].
(D) Metal-enhanced fluorescence (MEF): this means that the emission of fluorophore at a certain distance from metal nanostructures $(5-10 \mathrm{~nm})$ can increase. This is an interesting sensor for increasing the detection limit of target molecules (Figure 10) [41-44].

\section{Conclusion}

Metal nanostructures with optical, electrical, magnetic, and chemical properties have attracted much research not only scientifically but also in technological applications. To control the morphology of metal nanostructures, special synthesis methods are used, the most important of which is the use of prefabricated patterns or hard molds such as 
anodic aluminum oxide and soft molds such as cetyltrimethylammonium bromide (CTAB). Important and new applications of metal nanoparticles with different morphology and dimensions are their use in fuel cells, catalysts, and various sensors such as chemical sensors, colorimeters, and fluorescence.

\section{Data Availability}

No data were used to support this study.

\section{Conflicts of Interest}

The authors declare that they have no conflicts of interest.

\section{References}

[1] U. Y. Qazi and R. Javaid, "A review on metal nanostructures: preparation methods and their potential applications," Advances in Nanoparticles, vol. 05, no. 01, pp. 27-43, 2016.

[2] A. Pligovka, A. Poznyak, and M. Norek, "Optical properties of porous alumina assisted niobia nanostructured filmsdesigning 2-D photonic crystals based on hexagonally arranged nanocolumns," Micromachines, vol. 12, no. 6, p. $589,2021$.

[3] S. Said, S. Mikhail, and M. Riad, "Recent processes for the production of alumina nano-particles," Materials Science for Energy Technologies, vol. 3, pp. 344-363, 2020.

[4] P. M. Pletnev, V. M. Pogrebenkov, V. I. Vereshchagin, and D. S. Tyul'kin, "Mullite-corundum materials based on mullite binder resistant to high-temperature deformation," Refractories and Industrial Ceramics, vol. 58, no. 6, pp. 618-625, 2018.

[5] R. Zotov, E. Meshcheryakov, A. Livanova et al., "Influence of the composition, structure, and physical and chemical properties of aluminium-oxide-based sorbents on water adsorption ability," Materials, vol. 11, no. 1, p. 132, 2018.

[6] G. F. Leal, S. Lima, I. Graça et al., "Design of nickel supported on water-tolerant $\mathrm{Nb} 2 \mathrm{O} 5$ catalysts for the hydrotreating of lignin streams obtained from lignin-first biorefining," iScience, vol. 15, pp. 467-488, 2019.

[7] C. Gómez and J. Rodríguez-Páez, "The effect of the synthesis conditions on structure and photocatalytic activity of $\mathrm{Nb} 2 \mathrm{O} 5$ nanostructures," Process. Appl. Ceram.vol. 12, pp. 218-229, 2018.

[8] A. J. Dos Santos, L. M. B. Batista, C. A. Martínez-Huitle, A. P. d. M. Alves, and S. Garcia-Segura, "Niobium oxide catalysts as emerging material for textile wastewater reuse: photocatalytic decolorization of azo dyes," Catalysts, vol. 9, no. 12, p. 1070, 2019.

[9] S.-H. Lee, J.-D. Kwon, J.-H. Ahn, and J.-S. Park, "Compositional and electrical modulation of niobium oxide thin films deposited by plasma-enhanced atomic layer deposition," Ceramics International, vol. 43, no. 8, pp. 6580-6584, 2017.

[10] N. Hossain, O. Günes, C. Zhang et al., "Structural and physical properties of $\mathrm{NbO} 2$ and $\mathrm{Nb} 2 \mathrm{O} 5$ thin films prepared by magnetron sputtering," Journal of Materials Science: Materials in Electronics, vol. 30, no. 10, pp. 9822-9835, 2019.

[11] Y. Jia, M. Zhong, F. Yang et al., "Theoretical and experimental study on exciton properties of TT-, T-, and H-Nb2O5," Journal of Physical Chemistry C, vol. 124, no. 28, pp. 15066-15075, 2020.
[12] J. Stoever, J. E. Boschker, S. Bin Anooz et al., “Approaching the high intrinsic electrical resistivity of $\mathrm{NbO} 2$ in epitaxially grown films," Applied Physics Letters, vol. 116, no. 18, Article ID 182103, 2020.

[13] A. Poznyak, A. Pligovka, T. Laryn, and M. Salerno, "Porous alumina films fabricated by reduced temperature sulfuric acid anodizing: morphology, composition and volumetric growth," Materials, vol. 14, no. 4, p. 767, 2021.

[14] M. Altomare, G. Cha, and P. Schmuki, "Anodic nanoporous niobium oxide layers grown in pure molten ortho-phosphoric acid," Electrochimica Acta, vol. 344, Article ID 136158, 2020.

[15] A. B. Tesler, M. Altomare, and P. Schmuki, "Morphology and optical properties of highly ordered $\mathrm{TiO} 2$ nanotubes grown in NH4F/o-H3PO4 electrolytes in view of light-harvesting and catalytic applications," ACS Applied Nano Materials, vol. 3, no. 11, pp. 10646-10658, 2020.

[16] J. E. Yoo and P. Schmuki, "Critical factors in the anodic formation of extremely ordered titania nanocavities," Journal of the Electrochemical Society, vol. 166, no. 11, pp. C3389-C3398, 2019.

[17] B. N. Nunes, O. F. Lopes, A. O. T. Patrocinio, and D. W. Bahnemann, "Recent advances in niobium-based materials for photocatalytic solar fuel production," Catalysts, vol. 10, no. 1, p. 126, 2020.

[18] F. Shen, Z. Sun, Q. He, J. Sun, R. B. Kaner, and Y. Shao, "Niobium pentoxide based materials for high rate rechargeable electrochemical energy storage," Materials Horizons, vol. 8, no. 4, pp. 1130-1152, 2021.

[19] R. Georgiev, K. Lazarova, M. Vasileva, and T. Babeva, "All niobia Bragg stacks for optical sensing of vapors," Optical and Quantum Electronics, vol. 52, no. 2, p. 114, 2020.

[20] M. Ashurov, V. Gorelik, K. Napolskii, and S. Klimonsky, "Anodic alumina photonic crystals as refractive index sensors for controlling the composition of liquid mixtures," Photonic Sensors, vol. 10, no. 2, pp. 147-154, 2020.

[21] A. I. Sadykov, S. E. Kushnir, N. A. Sapoletova, V. K. Ivanov, and K. S. Napolskii, "Anodic titania photonic crystals with high reflectance within photonic band gap via pore shape engineering," Scripta Materialia, vol. 178, pp. 13-17, 2020.

[22] C. Wang, P. Qin, D. Lv, J. Wan, S. Sun, and H. Ma, "Characterization of anisotropy of the porous anodic alumina by the Mueller matrix imaging method," Optics Express, vol. 28, no. 5, pp. 6740-6754, 2020.

[23] A. J. Goszczak and P. P. Cielecki, "A review on anodic aluminum oxide methods for fabrication of nanostructures for organic solar cells," Current Nanoscience, vol. 15, no. 1, pp. 64-75, 2018.

[24] E. O. Gordeeva, I. V. Roslyakov, and K. S. Napolskii, “Aluminium anodizing in selenic acid: electrochemical behaviour, porous structure, and ordering regimes," Electrochimica Acta, vol. 307, pp. 13-19, 2019.

[25] D. Mudusu, K. R. Nandanapalli, S. R. Dugasani, J. W. Kang, S. H. Park, and C. W. Tu, "Growth of single-crystalline cubic structured tin(II) sulfide (SnS) nanowires by chemical vapor deposition," RSC Advances, vol. 7, no. 66, pp. 41452-41459, 2017.

[26] H. M. Chen, C. F. Hsin, P. Y. Chen et al., "Ferromagnetic CoPt3Nanowires: structural evolution from fcc to ordered L12," Journal of the American Chemical Society, vol. 131, no. 43, pp. 15794-15801, 2009.

[27] L. Liu, O. Albrecht, E. Pippel, K. Nielsch, and U. Gösele, “A novel synthesis of ultrathin CoPt3 nanowires by dealloying 
larger diameter Co99Pt1 nanowires and subsequent stressinduced crack propagation," Electrochemistry Communications, vol. 12, no. 6, pp. 835-838, 2010.

[28] B. Mohan Mundotiya, W. Ullah, Morphology controlled synthesis of the nanostructured gold by electrodeposition techniques," in Novel Metal Electrodeposition and the Recent ApplicationMasato Sone and Kazuya Masu, IntechOpen, 2018.

[29] Y. Si, M. Chen, and L. Wu, "Syntheses and biomedical applications of hollow micro-/nano-spheres with largethrough-holes," Chemical Society Reviews, vol. 45, no. 3, pp. 690-714, 2016.

[30] X. Zhang, Q. Guo, and D. Cui, "Recent advances in nanotechnology applied to biosensors," Sensors, vol. 9, no. 2, pp. 1033-1053, 2009.

[31] M. Chen, M. Hassan, H. Li, and Q. Chen, "Fluorometric determination of lead(II) by using aptamer-functionalized upconversion nanoparticles and magnetite-modified gold nanoparticles," Microchimica Acta, vol. 187, p. 85, 2020.

[32] B. Wen, J. Xue, X. Zhou et al., "Highly selective and sensitive detection of $\mathrm{Pb} 2+$ in aqueous solution using tetra(4-pyridyl) porphyrin-functionalized Thermosensitive ionic microgels," ACS Applied Materials \& Interfaces, vol. 10, no. 30, pp. 25706-25716, 2018.

[33] X. Niu, Y. Zhong, R. Chen, F. Wang, Y. Liu, and D. Luo, “A "turn-on" fluorescence sensor for $\mathrm{Pb} 2+$ detection based on graphene quantum dots and gold nanoparticles," Sensors and Actuators B: Chemical, vol. 255, pp. 1577-1581, 2018.

[34] D. Zhang, M. Zhu, L. Zhao et al., "Ratiometric fluorescent detection of $\mathrm{Pb} 2+$ by FRET-based phthalocyanine-porphyrin dyads," Inorganic Chemistry, vol. 56, no. 23, pp. 14533-14539, 2017.

[35] S. A. Jasim, M. M. Kadhim, V. Kn, and I. Raya, "Molecular junctions: introduction and physical foundations, nanoelectrical conductivity and electronic structure and charge transfer in organic molecular junctions," Brazilian Journal of Physics, vol. 52, p. 31, 2022.

[36] N. A. Khan, A. Niaz, M. I. Zaman, F. A. Khan, M. Nisar-ulhaq, and M. Tariq, "Sensitive and selective colorimetric detection of $\mathrm{Pb} 2+$ by silver nanoparticles synthesized from Aconitum violaceum plant leaf extract," Materials Research Bulletin, vol. 102, pp. 330-336, 2018.

[37] M. Chen, F. Y. H. Kutsanedzie, W. Cheng, A. A. Agyekum, $\mathrm{H}$. Li, and Q. Chen, "A nanosystem composed of upconversion nanoparticles and $\mathrm{N}, \mathrm{N}$-diethyl-p-phenylenediamine for fluorimetric determination of ferric ion," Microchimica Acta, vol. 185, no. 8, p. 378, 2018.

[38] M. Chen, F. Y. H. Kutsanedzie, W. Cheng, H. Li, and Q. Chen, "Ratiometric fluorescence detection of $\mathrm{Cd} 2+$ and $\mathrm{Pb} 2+$ by inner filter-based upconversion nanoparticledithizone nanosystem," Microchemical Journal, vol. 144, pp. 296-302, 2019.

[39] A. M. Demin, A. V. Mekhaev, A. A. Esin et al., "Immobilization of PMIDA on Fe3O4 magnetic nanoparticles surface: mechanism of bonding," Applied Surface Science, vol. 440, pp. 1196-1203, 2018.

[40] Please give necessary details for this reference.

[41] H. Li, Q. Chen, M. M. Hassan et al., “AuNS@Ag core-shell nanocubes grafted with rhodamine for concurrent metalenhanced fluorescence and surfaced enhanced Raman determination of mercury ions," Analytica Chimica Acta, vol. 1018, pp. 94-103, 2018.
[42] K. Saha, S. S. Agasti, C. Kim, X. Li, and V. M. Rotello, "Gold nanoparticles in chemical and biological sensing," Chemical Reviews, vol. 112, no. 5, pp. 2739-2779, 2012 May.

[43] B. Dong, H. Li, G. Mujtaba Mari et al., "Fluorescence immunoassay based on the inner-filter effect of carbon dots for highly sensitive amantadine detection in foodstuffs," Food Chemistry, vol. 294, pp. 347-354, 2019.

[44] Y. Jeong, Y. M. Kook, K. Lee, and W. G. Koh, "Metal enhanced fluorescence (MEF) for biosensors: general approaches and a review of recent developments," Biosensors and Bioelectronics, vol. 111, pp. 102-116, 2018.

[45] M. Salimi, V. Pirouzfar, and E. Kianfar, "Enhanced gas transport properties in silica nanoparticle filler-polystyrene nanocomposite membranes," Colloid \& Polymer Science, vol. 295, no. 1, pp. 215-226, 2017.

[46] M. Salimi, V. Pirouzfar, and E. Kianfar, "Novel nanocomposite membranes prepared with PVC/ABS and silica nanoparticles for C2H6/CH4 separation," Polymer Science Series A, vol. 59, no. 4, pp. 566-574, 2017.

[47] F. Kianfar and E. Kianfar, "Synthesis of isophthalic acid/aluminum nitrate thin film nanocomposite membrane for hard water softening," Journal of Inorganic and Organometallic Polymers and Materials, vol. 29, no. 6, pp. 2176-2185, 2019.

[48] E. Kianfar, "Nanozeolites: synthesized, properties, applications," Journal of Sol-Gel Science and Technology, vol. 91, no. 2, pp. 415-429, 2019.

[49] H. Liu and E. Kianfar, "Investigation the synthesis of nanoSAPO-34 catalyst prepared by different templates for MTO process," Catalysis Letters, 2020.

[50] E. Kianfar, M. Baghernejad, and Y. Rahimdashti, "Study synthesis of vanadium oxide nanotubes with two template hexadecylamin and hexylamine," Biological Forum, vol. 7, pp. 1671-1685, 2015.

[51] E. kianfar, Synthesizing of Vanadium Oxide Nanotubes Using Hydrothermal and Ultrasonic Method, pp. 1-80, Lambert Academic Publishing, Publisher, 2020.

[52] Z. Yang, L. Zhang, Y. Zhou, H. Wang, L. Wen, and E. Kianfar, "Investigation of effective parameters on SAPO34 nanocatalyst in the methanol-to-olefin conversion process: a review," Reviews in Inorganic Chemistry, vol. 41, no. 1, pp. 91-105, 2020.

[53] C. Gao, J. Liao, J. Lu, J. Ma, and E. Kianfar, "The effect of nanoparticles on gas permeability with polyimide membranes and network hybrid membranes: a review," Reviews in Inorganic Chemistry, 2020.

[54] E. Kianfar, M. Salimi, F. Kianfar, M. Kianfar, and S. A. H. Razavikia, "CO2/N2 separation using polyvinyl chloride iso-phthalic acid/aluminium nitrate nanocomposite membrane," Macromolecular Research, vol. 27, no. 1, pp. 83-89, 2019.

[55] E. Kianfar, "Production and identification of vanadium oxide nanotubes," Indian Journal of Science and Technology, vol. 8, no. S9, pp. 455-464, 2015.

[56] E. Kianfar, "Recent advances in synthesis, properties, and applications of vanadium oxide nanotube," Microchemical Journal, vol. 145, pp. 966-978, 2019.

[57] X. Huang, Y. Zhu, and E. Kianfar, "Nano biosensors: properties, applications and electrochemical techniques," Journal of Materials Research and Technology, vol. 12, pp. 1649-1672, 2021.

[58] E. Kianfar, "Protein nanoparticles in drug delivery: animal protein, plant proteins and protein cages, albumin nanoparticles," Journal of Nanobiotechnology, vol. 19, no. 1, p. 159, 2021. 
[59] E. Kianfar, "Magnetic nanoparticles in targeted drug delivery: a review," Journal of Superconductivity and Novel Magnetism, vol. 34, pp. 1709-1721, 2021.

[60] R. Syah, M. Zahar, and E. Kianfar, "Nanoreactors: properties, applications and characterization," International Journal of Chemical Reactor Engineering, vol. 19, no. 10, pp. 981-1007, 2021.

[61] I. Raya, H. H. Kzar, Z. H. Mahmoud, A. Al Ayub Ahmed, A. Z. Ibatova, and E. Kianfar, "A review of gas sensors based on carbon nanomaterial," Carbon Letters, 2021.

[62] S. E, C. He, J. H. Wang, Q. Mao, and X. Chen, “Tunable organelle imaging by rational design of carbon dots and utilization of uptake pathways," ACS Nano, vol. 15, no. 9, pp. 14465-14474, 2021.

[63] J. Chen, W.-R. Liu, Y. Li et al., "Architecting ultra-bright silanized carbon dots by alleviating the spin-orbit coupling effect: a specific fluorescent nanoprobe to label dead cells," Chemical Engineering Journal, vol. 428, Article ID 131168, 2022.

[64] J. Wu, J. H. Lei, B. He, C.-X. Deng, Z. Tang, and S. Qu, "Generating long-wavelength absorption bands with enhanced deep red fluorescence and photothermal performance in fused carbon dots aggregates," Aggregate, p. 49, 2021.

[65] D. Li, E. V. Ushakova, A. L. Rogach, and S. Qu, "Optical properties of carbon dots in the deep-red to near-infrared region are attractive for biomedical applications," Small, vol. 17, no. 43, Article ID 2102325, 2021.

[66] L. Rao, Q. Zhang, M. Wen et al., "Solvent regulation synthesis of single-component white emission carbon quantum dots for white light-emitting diodes," Nanotechnology Reviews, vol. 10, no. 1, pp. 465-477, 2021.

[67] S. Adorinni, M. C. Cringoli, S. Perathoner, P. Fornasiero, and S. Marchesan, "Green approaches to carbon nanostructurebased biomaterials," Applied Sciences, vol. 11, no. 6, p. 2490, 2021.

[68] T. Liang, E. Liu, M. Li et al., "Morphology control of luminescent carbon nanomaterials: from dots to rolls and belts,” ACS Nano, vol. 15, no. 1, pp. 1579-1586, 2021.

[69] J. Ni and Y. Li, "Carbon nanomaterials in different dimensions for electrochemical energy storage," Advanced Energy Materials, vol. 6, no. 17, Article ID 1600278, 2016.

[70] H. Chen, X.-L. Zhang, Y.-Y. Zhang et al., "Atomically precise, custom-design origami graphene nanostructures," Science, vol. 365, no. 6457, pp. 1036-1040, 2019.

[71] P. Jing, L. Sun, Y. An et al., "Near-infrared excitation/ emission and multiphoton-induced fluorescence of carbon dots," Advanced Materials, vol. 30, Article ID 1705913, 2018.

[72] K. Holá, M. Sudolská, S. Kalytchuk et al., "Graphitic nitrogen triggers red fluorescence in carbon dots," ACS Nano, vol. 11, no. 12, pp. 12402-12410, 2017.

[73] Y. Xiong, X. Zhang, A. F. Richter et al., "Chemically synthesized carbon nanorods with dual polarized emission," ACS Nano, vol. 13, no. 10, pp. 12024-12031, 2019.

[74] M. Zeiger, N. Jäckel, V. N. Mochalin, and V. Presser, "Review: carbon onions for electrochemical energy storage," Journal of Materials Chemistry, vol. 4, no. 9, pp. 3172-3196, 2016.

[75] M. Bartkowski and S. Giordani, "Supramolecular chemistry of carbon nano-onions," Nanoscale, vol. 12, no. 17, pp. 9352-9358, 2020.

[76] D. Li, P. Jing, L. Sun et al., "Near-infrared excitation/ emission and multiphoton-induced fluorescence of carbon dots," Advanced Materials, vol. 30, no. 13, Article ID 1705913, 2018.

[77] X. Bao, Y. Yuan, J. Chen et al., "in vivo theranostics with near-infrared-emitting carbon Dots.Highly efficient photothermal therapy based on passive targeting after intravenous administration," Light: Science \& Applications, vol. 7, pp. 1-11, 2018.

[78] Z. Tian, D. Li, E. V. Ushakova et al., "Multilevel Data encryption using thermal-treatment controlled room temperature phosphorescence of carbon dot/polyvinylalcohol composites," Advanced Science, vol. 5, no. 9, Article ID 1800795, 2018.

[79] X. Miao, D. Qu, D. Yang et al., "Synthesis of carbon dots with multiple color emission by controlled graphitization and surface functionalization," Advanced Materials, vol. 30, no. 1, Article ID 1704740, 2018.

[80] M. Kertesz, "Pancake bonding: an unusual pi-stacking interaction," Chemistry - A European Journal, vol. 25, no. 2, pp. 400-416, 2019.

[81] N. V. Tepliakov, E. V. Kundelev, P. D. Khavlyuk et al., "sp2sp3-Hybridized atomic domains determine optical features of carbon dots," ACS Nano, vol. 13, no. 9, pp. 10737-10744, 2019.

[82] J. R. Lakowicz, Ed., Principles of Fluorescence Spectroscopy, pp. 185-210, Springer Science \& Business Media, Maryland, Baltimore, 2013.

[83] F. Banhart and P. M. Ajayan, "Carbon onions as nanoscopic pressure cells for diamond formation," Nature, vol. 382, no. 6590, pp. 433-435, 1996.

[84] X. Li, X. Tu, S. Zaric et al., "Selective synthesis combined with chemical separation of single-walled carbon nanotubes for chirality selection," Journal of the American Chemical Society, vol. 129, no. 51, pp. 15770-15771, 2007.

[85] S. Che, "6 morphological control of AMSs," "Mesoporous Silica: By Anionic Amphiphilic Molecular Templates, pp. 67-100, De Gruyter, Berlin, Boston, USA, 2020.

[86] A. C. Rodrigo, S. M. Bromfield, E. Laurini, P. Posocco, S. Pricl, and D. K. Smith, "Morphological control of selfassembled multivalent (SAMul) heparin binding in highly competitive media," Chemical Communications, vol. 53, no. 47, pp. 6335-6338, 2017.

[87] J. Kim, Y. Song, H. Kim et al., "3D hierarchical polyanilinemetal hybrid nanopillars: morphological control and its antibacterial application," Nanomaterials, vol. 11, no. 10, p. 2716, 2021.

[88] M. A. Muflikhun, A. Y. Chua, and G. N. C. Santos, "Structures, morphological control, and antibacterial performance of $\mathrm{Ag} / \mathrm{TiO}_{2}$ micro-nanocomposite materials," Advances in Materials Science and Engineering, vol. 2019, Article ID 9821535, 12 pages, 2019.

[89] W. Yan, K. Liang, Z. Chi, T. Liu, M. Cao, and S. Fan, T. Xu, T. Liu, and J. Su, Litchi-like structured MnCo2S4@C as a high capacity and long-cycling time anode for lithium-ion batteries," Electrochimica Acta, vol. 376, Article ID 138035, 2021.

[90] W. Yan, M. Cao, S. Fan et al., "Multi-yolk ZnSe/2(CoSe2) @NC heterostructures confined in N-doped carbon shell for high-efficient sodium-ion storage," Composites Part B: Engineering, vol. 213, Article ID 108732, 2021.

[91] X. Zhang, Y. Tang, F. Zhang, and C.-S. Lee, "A novel aluminum-graphite dual-ion battery," Advanced Energy Materials, vol. 6, no. 11, Article ID 1502588, 2016.

[92] X. Tong, F. Zhang, B. Ji, M. Sheng, and Y. Tang, "Carboncoated porous aluminum foil anode for high-rate, long-term 
cycling stability, and high energy density dual-ion batteries," Advanced Materials, vol. 28, no. 45, pp. 9979-9985, 2016.

[93] M. Yang, Q. Kong, W. Feng, W. Yao, and Q. Wang, "Caged biomass carbon with anchoring $\mathrm{MoO} 2 / \mathrm{NC}$ Nanospheres: synergistic enhancement of potassium ion storage and electrochemical performance," Applied Surface Science, vol. 569, Article ID 150984, 2021.

[94] Y. Li, D. D. Macdonald, J. Yang, J. Qiu, and S. Wang, "Point defect model for the corrosion of steels in supercritical water: Part I, film growth kinetics," Corrosion Science, vol. 163, Article ID 108280, 2020.

[95] L. Li, Y. Shan, F. Wang et al., "Improving fast and safe transfer of lithium ions in solid-state lithium batteries by porosity and channel structure of polymer electrolyte," ACS Applied Materials \& Interfaces, vol. 13, no. 41, pp. 4852548535, 2021.

[96] Z. Zhang, R. Xun, L. Wang, and Z. Meng, "Construction of pseudocapacitive Li2-xLaxZnTi3O8 anode for fast and super-stable lithium storage," Ceramics International, vol. 47, no. 1, pp. 662-669, 2021.

[97] Y. Chen, M. Sang, W. Jiang et al., "Fracture predictions based on a coupled chemo-mechanical model with strain gradient plasticity theory for film electrodes of Li-ion batteries," Engineering Fracture Mechanics, vol. 253, Article ID 107866, 2021.

[98] L. Tan, Y. Sun, C. Wei et al., "Design of robust, lithiophilic, and flexible inorganic-polymer protective layer by separator engineering enables dendrite-free lithium metal batteries with LiNi0.8Mn0.1Co0.1O2 cathode," Small, vol. 17, no. 13, 2021.

[99] S. Mu, Q. Liu, P. Kidkhunthod, X. Zhou, W. Wang, and Y. Tang, "Molecular grafting towards high-fraction active nanodots implanted in $\mathrm{N}$-doped carbon for sodium dual-ion batteries," National Science Review, vol. 8, no. 7, 2020.

[100] M. Wang, C. Jiang, S. Zhang, X. Song, Y. Tang, and H.-M. Cheng, "Reversible calcium alloying enables a practical room-temperature rechargeable calcium-ion battery with a high discharge voltage," Nature Chemistry, vol. 10, no. 6, pp. 667-672, 2018.

[101] B. Ji, F. Zhang, X. Song, and Y. Tang, "A novel potassiumion-based dual-ion battery," Advanced Materials, vol. 29, no. 19, Article ID 1700519, 2017.

[102] I. Gullo, A. Marques, R. Pinto, and L. Crines, "alMorphological control for molecular testing: a practical approachJournal of," Clinical Pathology, vol. 74, pp. 331-333, 2021.

[103] B. Sadeghi, F. S. Garmaroudi, M. Hashemi, and H. R. Nezhad, "Comparison of the anti-bacterial activity on the nanosilver shapes: nanoparticles, nanorods and nanoplates," Advanced Powder Technology, vol. 23, no. 1, pp. 22-26, 2012.

[104] L. Shang, K. Nienhaus, and G. Nienhaus, "Engineered nanoparticles interacting with cells: size matters," Journal of Nanobiotechnology, vol. 12, no. 1, p. 5, 2014.

[105] M. A. Muflikhun, M. C. Frommelt, M. Farman, A. Y. Chua, and G. N. C. Santos, "Structures, mechanical properties and antibacterial activity of $\mathrm{Ag} / \mathrm{TiO} 2$ nanocomposite materials synthesized via HVPG technique for coating application," Heliyon, vol. 5, no. 4, pp. 1-21, 2019.

[106] M. J. Hajipour, K. M. Fromm, and A. Akbar Ashkarran, "Antibacterial properties of nanoparticles," Trends in Biotechnology, vol. 30, no. 10, pp. 499-511, 2012.

[107] W. V Espulgar and G. N. C. Santos, "Antimicrobial silver nanomaterials synthesized by HVPCG technique," International Journal of Scientific Engineering and Research, vol. 2, no. 8, pp. 8-11, 2011.
[108] J. Wang, W. Liu, and H. Li, "Preparation of cellulose fiberTiO2 nanobelt-silver nanoparticle hierarchically structured hybrid paper and its photocatalytic and antibacterial properties," Chemical Engineering Journal, vol. 228, pp. 272-280, 2013.

[109] S. Mei, H. Wang, W. Wang, and P. K. Chu, "Antibacterial effects and biocompatibility of titanium surfaces with graded silver incorporation in titania nanotubes," Biomaterials, vol. 35, no. 14, pp. 4255-4265, 2014.

[110] D.-H. Song, S.-H. Uhm, S.-B. Lee, J.-G. Han, and K.-N. Kim, "Antimicrobial silver-containing titanium oxide nanocomposite coatings by a reactive magnetron sputtering," Thin Solid Films, vol. 519, no. 20, pp. 7079-7085, 2011.

[111] M. V. Liga, E. L. Bryant, V. L. Colvin, and Q. Li, "Virus inactivation by silver doped titanium dioxide nanoparticles for drinking water treatment," Water Research, vol. 45, no. 2, pp. 535-544, 2011.

[112] F. Martinez-Gutierrez, P. L. Olive, and A. Banuelos, "Synthesis, characterization, and evaluation of antimicrobial and cytotoxic effect of silver and titanium nanoparticles," Nanomedicine: Nanotechnology, Biology and Medicine, vol. 6, no. 5, pp. 681-688, 2010.

[113] J. S. Gabriel, V. A. M. Gonzaga, A. L. Poli, and C. C. Schmitt, "Photochemical synthesis of silver nanoparticles on chitosans/montmorillonite nanocomposite films and antibacterial activity," Carbohydrate Polymers, vol. 171, pp. 202-210, 2017.

[114] X. Hong, J. Wen, X. Xiong, and Y. Hu, "Shape effect on the antibacterial activity of silver nanoparticles synthesized via a microwave-assisted method," Environmental Science and Pollution Research, vol. 23, no. 5, pp. 4489-4497, 2016.

[115] J. C. Briones, G. Castillon, M. P. Delmo, and G. N. C. Santos, "Magnetic-field-enhanced morphology of tin oxide nanomaterials for gas sensing applications," Journal of Nanomaterials, vol. 2017, Article ID 4396723, 11 pages, 2017.

[116] M. A. Muflikhun, A. Y. Chua, and G. N. C. Santos, "Statistical design analysis of silver-titanium dioxide nanocomposite materials synthesized via horizontal vapor Phase growth (HVPG)," Key Engineering Materials, vol. 735, pp. 210-214, 2017.

[117] S. Patra, S. Mukherjee, A. K. Barui, A. Ganguly, B. Sreedhar, and C. R. Patra, "Green synthesis, characterization of gold and silver nanoparticles and their potential application for cancer therapeutics," Materials Science and Engineering: $C$, vol. 53, pp. 298-309, 2015.

[118] G. R. Nasretdinova, R. R. Fazleeva, R. K. Mukhitova, and V. V. Yanilkin, "Electrochemical mediated synthesis of silver nanoparticles in solution," Russian Journal of Electrochemistry, vol. 51, no. 11, pp. 1029-1040, 2015.

[119] O. Beier, A. Pfuch, K. Horn, J. Weisser, M. Schnabelrauch, and A. Schimanski, "Low temperature deposition of antibacterially active silicon oxide layers containing silver nanoparticles, prepared by atmospheric pressure plasma chemical vapor deposition," Plasma Processes and Polymers, vol. 10, no. 1, pp. 77-87, 2013.

[120] Z. Khan, S. A. Al-Thabaiti, A. Y. Obaid, and A. O. Al-Youbi, "Preparation and characterization of silver nanoparticles by chemical reduction method," Colloids and Surfaces B: Biointerfaces, vol. 82, no. 2, pp. 513-517, 2011.

[121] F. Baghbani-arani, R. Movagharnia, A. Sharifian, S. Salehi, S. A. S. Shandiz, and S. Shandiz, "Photo-catalytic, antibacterial, and anti-cancer properties of phyto-mediated synthesis of silver nanoparticles from artemisia tournefortiana Rchb extract," Journal of Photochemistry and Photobiology B: Biology, vol. 173, pp. 640-649, 2017. 
[122] S. J. Lee, M. Heo, D. Lee, and K. Kwon, "Preparation and characterization of antibacterial orthodontic resin containing silver nanoparticles," Applied Surface Science, vol. 432, pp. 317-323, 2018.

[123] H. Cao, X. Liu, F. Meng, and P. K. Chu, "Biological actions of silver nanoparticles embedded in titanium controlled by micro-galvanic effects," Biomaterials, vol. 32, no. 3, pp. 693-705, 2011.

[124] S. Sarkar, A. D. Jana, S. K. Samanta, and G. Mostafa, "Facile synthesis of silver nano particles with highly efficient antimicrobial property," Polyhedron, vol. 26, no. 15, pp. 4419-4426, 2007.

[125] C. Fu, A. Rahmani, W. Suksatan et al., "Comprehensive investigations of mixed convection of Fe-ethylene-glycol nanofluid inside an enclosure with different obstacles using lattice Boltzmann method," Scientific Reports, vol. 11, no. 1, pp. 1-16, 2021.

[126] T. Tjahjono, M. Elveny, S. Chupradit, D. Bokov, H. T. Hoi, and M. Pandey, "Role of Cryogenic Cycling Rejuvenation on Flow Behavior of $\mathrm{ZrCuAlNiAg}$ Metallic Glass at Relaxation Temperature," Transactions of the Indian Institute of Metals, vol. 74, pp. 1-7, 2021.

[127] A. Shawi, S. Ghazi, S. Aravindhan, L. Thangavelu, A. Elena, and R. Rafkatovna Zakieva, "Synthesis of NiO nanoparticles and sulfur, and nitrogen co doped-graphene quantum dots/ $\mathrm{NiO}$ nanocomposites for antibacterial application," Journal of Nanostructures, vol. 11, no. 1, pp. 181-188, 2021.

[128] H. Watandost, J. Achak, and A. Haqmal, "Oxidation of hydrogels based of sodium alginate and $\mathrm{MnO} 2$ as catalyst," International Journal of Innovative Research and Scientific Studies, vol. 4, no. 4, pp. 191-199, 2021, https://doi.org/10. 53894/ijirss.v4i4.77.

[129] S. Hutapea, S. Ghazi Al-Shawi, T. C. Chen et al., "Study on Food Preservation Materials Based on Nano-Particle Reagents," Food Science and Technology, 2021.

[130] N. Ngafwan, H. Rasyid, E. S. Abood et al., "Study on Novel Fluorescent Carbon Nanomaterials in Food Analysis," Food Science and Technology, 2021.

[131] S. Alwan, M. Al-Saeed, and H. Abid, "Safety assessment and biochemical evaluation of biogenic silver nanoparticles (using bark extract of C. zeylanicum) in Rattus norvegicus rats: safety of biofabricated AgNPs (using Cinnamomum zeylanicum extract)," Baghdad Journal of Biochemistry and Applied Biological Sciences, vol. 2, no. 03, pp. 138-150, 2021.

[132] K. E. Korte, S. E. Skrabalak, and Y. Xia, "Rapid synthesis of silver nanowires through a $\mathrm{CuCl}$ or $\mathrm{CuCl} 2$ mediated polyol process," Journal of Materials Chemistry, vol. 18, pp. 437441, 2008.

[133] C. Yee, M. Scotti, A. Ulman, H. White, M. Rafailovich, and J. Sokolov, "One phase synthesis of thiol functionalized platinum nanoparticles," Langmuir, vol. 15, pp. 4314-4316, 1999.

[134] T. Teranishi, M. Hosoe, T. Tanaka, and M. Miyake, "Size control of monodispersed Pt nanoparticles and their 2D organization by electrophoretic deposition," Journal of Physical Chemistry, vol. 103, pp. 3818-3827, 1999.

[135] X. Wu, P. L. Redmond, H. Liu, Y. Chen, M. Steigerwald, and L. Brus, "Photovoltage mechanism for room light conversion of citrate stabilized silver nanocrystal seeds to large nanoprisms," Journal of the American Chemical Society, vol. 130, pp. 9500-9506, 2008.

[136] U. Y. Qazi, S. Kajimoto, and H. Fukumura, "Effect of sodium dodecyl sulfate on the formation of silver nanoparticles by biphotonic reduction of silver nitrate in water," Chemistry Letters, vol. 43, pp. 1693-1695, 2014.
[137] P. Y. Lim, R. S. Liu, P. L. She, C. F. Hung, and H. C. Shih, "Synthesis of Ag nanospheres particles in ethylene glycol by electrochemical assisted polyol process," Chemical Physics Letters, vol. 420, pp. 304-308, 2006.

[138] J. Zhang, S. Li, J. Wu, G. Schatz, and C. Mirkin, "Plasmon mediated synthesis of silver triangular bipyramids," Angewandte Chemie International Edition, vol. 48, pp. 7927-7931, 2009.

[139] E. Haro-Poniatowski, N. Batina, M. C. Acosta-Garca et al., "UV laser irradiation effects on silver nanostructures," Radiation Effects and Defects in Solids, vol. 162, pp. 491-499, 2007.

[140] V. K. Sharma, R. A. Yngard, and Y. Lin, "Silver nanoparticles: green synthesis and their antimicrobial activities," Advances in Colloid and Interface Science, vol. 145, pp. 83-96, 2009.

[141] Z. Qiaoxin, L. Hao, W. Xiaohui, S. Xiaoliang, and D. Xinglong, "Fabrication and characterization of nano silver powder prepared by spray pyrolysis," Journal of Wuhan University of Technology-Materials Science Edition, vol. 24, pp. 871-874, 2009.

[142] A. L. Koh, K. Bao, I. Khan et al., "Electron energy loss spectroscopy (EELS) of surface plasmons in single silver nanoparticles and dimers: influence of beam damage and mapping of dark modes," ACS Nano, vol. 3, pp. 3015-3022, 2009.

[143] J. P. Camden, J. A. Dieringer, Y. Wang et al., "Probing the structure of single molecule surface enhanced Raman scattering hot spots," Journal of the American Chemical Society, vol. 130, pp. 12616-12617, 2008.

[144] Z. S. Pillai and P. V. Kamat, "What factors control the size and shape of silver nanoparticles in the citrate ion reduction method?" Journal of Physical Chemistry B, vol. 108, pp. 945-951, 2004.

[145] P. C. Lee and D. Meisel, "Adsorption and surface enhanced Raman of dyes on silver and gold sols," Journal of Physical Chemistry, vol. 86, pp. 3391-3395, 1982.

[146] A. Henglein and M. Giersig, "formation of colloidal silver nanoparticles: capping action of citrate," Journal of Physical Chemistry B, vol. 103, pp. 9533-9539, 1999.

[147] X. Dong, X. Ji, H. Wu, L. Zhao, J. Li, and W. Yang, "Shape control of silver nanoparticles by stepwise citrate reduction," Journal of Physical Chemistry C, vol. 113, pp. 6573-6576, 2009.

[148] A. R. Tao, S. Habas, and P. Yang, "Shape control of colloidal metal nanocrystals," Small, vol. 4, pp. 310-325, 2008.

[149] Y. Sun and Y. Xia, "Shape controlled synthesis of gold and silver nanoparticles," Science, vol. 298, pp. 2176-2179, 2002.

[150] Q. Zhang, W. Li, C. Moran, J. Chen, L. P. Wen, and Y. Xia, "Seed mediated synthesis of Ag nanocubes with controllable edge lengths in the range of 30-200 nm and comparison of their optical properties," Journal of the American Chemical Society, vol. 132, pp. 11372-11378, 2010.

[151] N. R. Jana, L. Gearheart, and C. J. Murphy, "Seed mediated growth approach for shape controlled synthesis of spheroidal and rod like gold nanoparticles using a surfactant template," Advanced Materials, vol. 13, pp. 1389-1393, 2001.

[152] B. Pietrobon, M. McEachran, and V. Kitaev, "Synthesis of size controlled faceted pentagonal silver nanorods with tunable plasmonic properties and self assembly of these nanorods," ACS Nano, vol. 3, pp. 21-26, 2008.

[153] Y. Sun, Y. Yin, B. T. Mayers, T. Herricks, and Y. Xia, "Uniform silver nanowires synthesis by reducing AgNO3 with ethylene glycol in the presence of seeds and poly(vinyl pyrrolidone)," Chemistry of Materials, vol. 14, pp. 47364745, 2002. 
[154] J. Liebigs, "Ueber Versilberung und Vergoldung von Glas," Annalen der Chemie und Pharmacie, vol. 98, pp. 132-139, 1856.

[155] R. M. Garcia, Y. Song, R. M. Dorin et al., “Templated growth of platinum nanowheels using the inhomogeneous reaction environment of bicelles," Physical Chemistry Chemical Physics, vol. 13, pp. 4846-4852, 2011.

[156] X. Huang, Y. Li, Y. Chen, H. Zhou, X. Duan, and Y. Huang, "Plasmonic and catalytic AuPd nanowheels for the efficient conversion of light into chemical energy," Angewandte Chemie, vol. 125, pp. 6179-06183, 2013.

[157] K. G, H. J. Kim, and S. U. Son, "Low temperature synthesis of ultrathin rhodium nanoplates via molecular orbital symmetry interaction between rhodium precursors," Chemistry of Materials, vol. 22, pp. 1273-1275, 2010.

[158] H. Guo, Y. Chen, H. Ping, L. Wang, and D. L. Peng, "One pot synthesis of hexagonal and triangular nickel copper alloy nanoplates and their magnetic and catalytic properties," Journal of Materials Chemistry, vol. 22, pp. 8336-8344, 2012.

[159] Q. Zhang, N. Li, J. Goebl, Z. Lu, and Y. Yin, "A systematic study of the synthesis of silver nanoplates: is citrate a "magic" reagent?" Journal of the American Chemical Society, vol. 133, pp. 18931-18939, 2011.

[160] H. Shen, P. Bienstman, and B. Maes, "Plasmonic absorption enhancement in organic solar cells with thin active layers," Journal of Applied Physics, vol. 106, Article ID 073109, 2009.

[161] K. F. MacDonald, Z. L. Samson, M. I. Stockman, and N. I. Zheludev, "Ultrafast active plasmonics," Nature Photonics, vol. 3, pp. 55-58, 2009.

[162] T. Shegai, Y. Huang, H. Xu, and M. Kall, "Coloring fluorescence emission with silver nanowires," Applied Physics Letters, vol. 96, Article ID 103114, 2010.

[163] Z. Ma, X. Zhang, X. Guo, Q. Yang, Y. Ma, and L. Tong, "Surface Plasmon excitation in silver nanowires directly deposited on a laser diode chip," Applied Physics Letters, vol. 96, Article ID 051119, 2010. 